\title{
Carbamoyl-phosphate synthetase 1 deficiency
}

INSERM

\section{Source}

INSERM. (1999). Orphanet: an online rare disease and orphan drug data base.

Carbamoyl-phosphate synthetase 1 deficiency. ORPHA:147

Carbamoyl-phosphate synthetase 1 deficiency (CPS1D) is a rare and severe disorder of urea cycle metabolism most commonly characterized by either a neonatal-onset of severe hyperammonemia that occurs few days after birth and manifests with lethargy, vomiting, hypothermia, seizures, coma and death or a presentation outside the newborn period at any age with (sometimes) milder symptoms of hyperammonemia. 